\title{
MAKING SENSE OF CORRUPTION, BY BO ROTHSTEIN AND AIYSHA VARRAICH (CAMBRIDGE UNIVERSITY PRESS, 2017)
}

\author{
CIBELE SILVA E SOUZA ${ }^{1}$
}

Looking back at the period before the 1990s, it is possible to note that corruption-related issues tended not to be part of the news schedule, much less an element of everyday conversation. In contemporaneity, this perspective has changed, since the theme has gained space in the social repertoire and in empirical research through the related diversity of terms, whereby corruption can be deemed an "umbrella concept" due to its multidimensional mode in relation to its universality and effects.

In this context, the presentation of a map of the evolution and universalization of the term, in dialogue with the perspectives of the sociological, anthropological and political sciences, can help with understanding the intricacies of the topic of corruption since the 1990s. In several studies, corruption is perceived not only as a form of backwardness in societies, but also as a barrier to democracy. Emphasizing this, one of the difficulties is that the term in academia and even in society in general is broadly framed by various conceptualizations and definitions, such as patronage, patrimonialism, particularism, and state capture, which reflect the multidimensionality of corruption and its universality and effects. In addition to this we may contribute the relationship between the biblical concept and its religious and moral foundations, as well as that defined by the Oxford English Dictionary.

In an attempt to answer the question that they raise about the importance of conceptualizing and theorizing corruption, Bo Rothstein and Aiysha Varraich reflect on the various multidimensional senses of corruption through a deep analysis that discusses the revolution and ramification of the concept. Bearing in mind that the possibility of creating a universal understanding of the concept of corruption becomes increasingly distant because languages do not share the

1 Cibele Silva e Souza is a Ph.D. student at the Institute of Sociology and Social Policy at Corvinus University of Budapest; e-mail: cibeleufop@gmail.com 
same terms (reinforcing claims to a universality of meanings), however, does not change the meaning of the term.

The argument presented in the book revolves around the issue of the importance of definitions and terms (surrounding the word corruption) in the academic environment, along with ways of assessing corruption and what constitutes the opposite of the term. As the authors state, the "intention is to map the landscape of different conceptualizations of corruption and related concepts such as clientelism, patronage, particularism, state capture and patrimonialism" (p. 9).

In exposing the idea of the map of the evolution and universalization of the term in various fields, the authors point out that one of the reasons for the big repercussions of the use of the term corruption originates in the speech of the World Bank President James Wolfensohn in 1990. After that pronouncement many international organizations became interested in the problem, because in that decade the concept of corruption was reformulated as an economic problem.

The fact that ideas about corruption have been reoriented in the political field is related to the importance placed on "good governance." As the authors claim, "since corruption tends to be a sensitive issue, the 'coded language' for this policy re-orientation has been to stress the importance of 'good governance'. A typical statement comes from former United Nations General Secretary Kofi Annan: 'Good governance is perhaps the single most important factor in eradicating poverty and promoting development' (UN 1998)" (p.2).

From this approach, the sociological perspective of "good governance," one of the issues addressed in relation to the topic and a recurring factor of reflection, is the impossibility of measuring the level of corruption between societies, even in studies or research that take into account variations in the concept in relation to time and the diversity that exists in each region. From this perspective, the authors argue that measures aimed at moderating corruption and improving the quality of government have effects on human well-being, in view of the fact that representative democracy should be driven by competence, impartiality, incorruptibility, and honesty for the purpose of effectively promoting human well-being.

The authors mention that the concept of corruption is neither Western, nor new, but universal and not limited by the liberal Western world. Thus, the concept of corruption as a "general disease of the body politic was also central to the thinking of Enlightenment thinkers such as Machiavelli, Montesquieu and Rousseau" (p. 35).

Bo Rothstein and Aiysha Varraich begin with the difference between republicanism and liberalism to explain the constitution of a "good society." From this perspective, they mention that "in liberal thought, the role of politics 
in 'good society' is to dominate others" (p 37). On the other hand, in republican thinking, "good society" is a problem of collective action: agents seek selfinterest, which consequently creates the risk of destroying the possibilities of contributing to or creating common goods, or acting in the public interest. This, according to the authors, tends to occur in public administration, where individual opportunism might contribute to the social trap of mistrust and hence corruption. Thus, in this context, "the genuine dilemma in all such collective action/social trap types of situations is how to balance the tension created between private self-interest and 'public good"' (p. 38).

Another factor that is addressed that confers on corruption a multidimensional dimension is the fact that corruption has been treated academically by different disciplines over time, and therefore each of these fields of approach has its own understanding - without, however, arriving at a consensus about the definition and conceptualization of corruption. From this perspective, Rothstein and Varraich proffer an introduction to how these studies of corruption have become important in the investigations of each discipline, with consideration of how the empirical studies have dealt with each field, besides presenting contextualizations, definitions, and examples from the economic and social field.

Schematically, as an example, the authors mention that academic corruption studies are divided into three fields: Corruption in Legal Studies, Corruption from Sociological and Anthropological Perspectives, and Corruption as an Economic Issue. With regard to corruption in legal studies, the authors maintain that any act performed by officials in exchange for legal advantage is an example of corruption. From this perspective, a definition of corruption exists in the legal field in order to identify the correct criteria to define the theme; however, one of the problems pointed out in terms of the legal definitions of corruption is that they exclude many other definitions, such as favoritism, favor exchanges, and other non-cash conceptions.

In dealing with corruption from sociological and anthropological perspectives, the authors claim that social studies that investigate the link between the state and people effectively focus on society at large, with the ideological center being state society, which may be analyzed to understand the operation of societal corruption. Therefore, there is a tendency to observe organizational and rational organizational behavior turning towards corruption in association with the state (organization).

In exploring this framework of meanings, the concept of corruption in the economic field (as an economic phenomenon) is identified as an impediment to economic growth in the development of nations. Thus, the authors reinforce the claim that studies of economic phenomenon are not only linked to economic 
advantages but also to public funds, industrial organizations, and economic crimes.

When addressing the social aspect, corruption is understood to be linked to interpersonal domination. The authors state that all these terms encompass corruption, although further concepts have been established in their own categories, there being an "overlapping of concepts" which is not fully exposed in the literature. With this in mind, the authors seek to close this gap by delineating conceptualizations of forms of corruption and analyzing the overlap between each of these concepts.

In dealing with the evolution of the concept of corruption, guided by the review of concepts, the authors mention that both moral and political views are key to understanding corruption, and these factors reinforce this statement.

Faced with the range of factors that contribute to the diversity of terms, the authors point out that corruption is used as a filter to connect relevant concepts such as clientelism, patrimonialism, patronage, and state capture. Having that in mind, the authors cite that clientelism tends to be used in countries in transition in Southeast Asia, post-communist states, and Latin America. State capture, however, is approached with the example of private-sector lobbying in the United States, which as the authors mention, is the "youngest [form] and viewed as a clear type of corruption" (p. 94).

Patrimonialism is the most popular form of corruption on the African continent and the term Patronage applies to the corruption of developed countries, while being considered by others as "machine politics." With this in mind, Rothstein and Varraich reinforce the idea of different types of concepts, although these are dealt with in a literary way with the same theoretical perspective, generating confusion about how to clarify them.

In endorsing the relationship between corruption and patrimonialism, the authors mention Max Weber, who used the term to explain the relation of patriarchal domination to research social structures and governance at the state level. Therefore, the former claim that Patrimonialism is commonly used as a synonym for corruption, especially when it comes to explaining the situation on the African continent. It is worth mentioning that the concept of patrimonialism deals with the idea of patron-client, and can be understood as the metamorphosis of clientelism and patronage. However, the book points out that the differences are linked to "who is exercising it [power]" (p. 90). Moreover, the book also highlights that paternalism is a form of government that originated from the concept of patriarchy, in which the focus becomes the core of the organization.

The authors note that patronage has different meanings since it is a theme much used in contemporary times which tends to be linked to the political sciences. As the former discuss, in the field of political science patronage is defined as a 
"way of governing, an 'electoral tool' or an 'instrument for managing political relations"' (p. 80). In this way, it is explained that patronage to the political sciences involves exchange between patron and client, the particular objective of which is exchange of public office.

In relation to patronage and corruption, the authors recall recent studies which hold that corruption and patronage in practice are concepts that in a way resemble each other. Therefore, the book's interest is to investigate how patronage relates to the concept of corruption in order to assess how forms of patronage can be considered corrupt. Rothstein and Varraich argue that patronage is applied in a variety of ways, and their interest is in investigating how patronage relates to the concept of corruption in order to assess how forms of patronage can be considered corrupt, "the concept of party patronage is not as penetrating as corruption because it is done in the open and not under the table, as most corruption deals are. However the overlap into corruption is obvious when these appointments are done 'for the purpose of providing private kickbacks' or more so "in return for bribes"” (p. 86).

Assuming this narrative, the authors endorse the view that corruption and patronage overlap in different ways: "Patronage can at times 'lead' to corruption, while at other times it in itself is corruption" (p. 86). Regarding the concept of partisan sponsorship, they mention that the term does not tend to be as pervasive as corruption because it is more open and "not under the table, as most corruption deals are" (p. 86). However, the authors point to this as a different form of corruption, as it is obvious when appointments are made with the purpose of exchanging bribes.

According to the authors' point of view, state capture is one of the recurrent forms of corruption, being considered a gray act. In the dialogue, the authors emphasize that the state is corrupt when political tools and mechanisms operate in favor of private acts that generate social costs; the claim thus corresponds to material presented in the first chapter of the book. Hence, there is a result in the private field that comes from the public environment. Thus, the book holds that in relation to the other concepts of types of corruption that are presented with an emphasis on how power is exercised, state capture is a contrasting situation which "focuses directly on the input side of the equation, where corruption is affecting the basic rules of the game" (p. 94).

In summary, from reading the book Making sense of corruption it is concluded that corruption-related themes of previous years have undergone changes and variations, becoming more recurrent on agendas and in social investigations. As discussed by the authors, at present the discussion about corruption is part of not only the academic environment and anticorruption policies, but it is also an issue of human behavior in a globalized world that is focused on building good governance. 
In this sense, the book contributes to the conceptual explanation and clarification of corruption and its variants, providing evidence for some connections between the terms used in dialogue with reflections on the universal understanding of the term both socially and academically. Systematically, the book seeks to reflect on the term, its multidimensionality, and factors that contribute to its diversity.

Rothstein and Varraich show the breadth of studies related to the term and the various specifications and overlaps between each of these concepts, thereby raising questions and discussions. Based on the perspective that is offered, and taking into account the intricacies of corruption, the work represents a clear and cohesive analysis that will be of use when discussing the political system, impartiality, and good governance in an attempt to fill the gaps in the lack of a universal definition of corruption. For those who wish to delve into the intricacies of the concept of corruption, the book provides reflections on the multi-disciplinarity surrounding the term. 